\title{
Traumatic Pseudoaneurysm of the Superficial Temporal Artery in a Teenager: A Case Report
}

\author{
Chafiki Z , Ait-el-kerdoudi M, Naceur S, Rouadi S, Abada R, Roubal M and Mahtar M \\ Department of ENT, 20 Août hospital, Ibn Rochd University Hospital, Casablanca, Morocco
}

*Corresponding author: Chafiki Z, Department of ENT, 20 Août hospital, Ibn Rochd University Hospital, Casablanca, Morocco, E-mail: zakaria.chafiki@gmail.com

Citation: Chafiki Z, Ait-el-kerdoudi M, Naceur S, Rouadi S, Abada R, et al. (2016) Traumatic Pseudoaneurysm of the Superficial Temporal Artery in a Teenager: A Case Report. J Surg Oper Care 1(2): 203. doi: $10.15744 / 2455-7617.1 .203$

Received Date: January 14, 2016 Accepted Date: March 10, 2016 Published Date: March 14, 2016

\begin{abstract}
Traumatic pseudoaneurysm of the superficial temporal artery is a very rare lesion and usually presents as a painless pulsatile mass in the temporal region a few weeks after trauma. The infrequent incidence and sometimes perplexing presentation still warrants the need for awareness of its presentation and diagnosis. We report a case of traumatic pseudoaneurysm of the superficial temporal artery that presented a few weeks after blunt trauma to the head in an 18 year old. We also review the optimal approach to the diagnosis and management of the lesion.

Keywords: Pseudoaneurysm traumatic; Superficial temporal artery; Excision
\end{abstract}

\section{Introduction}

A pseudoaneurysm of the superficial temporal artery (STA) is an infrequent lesion, especially in children, and it has a characteristic finding of a pulsatile cystic mass in the frontotemporal region [1,2]. Thomas Bartholin first described a case of STA pseudoaneurysm in 1740 [3] and since then, more than 400 cases have been reported in the literature [4]. We report a case of pseudoaneurysm of the STA secondary to a head injury in a teenager and discuss the etiology, diagnosis, and treatment options.

\section{Case report}

A 18 year old teenager presented to the otorhinolaryngology outpatient department for a slowly growing preauricular mass which had appeared following an altercation 3 months previously where he had received a single slap to his left temple. On examination, we found a pulsatile, painless mass measuring approximately $25 \mathrm{~mm}$ in diameter (Figure 1). In addition, a bruit was audible over the mass using a stethoscope. A contrast enhanced CT scan revealed a well-enhancing round mass in the left temporal region (Figure 2 and 3). The patient underwent surgical excision of the lesion under general anesthesia. The mass was severely adherent to the adjacent tissue, and after complete dissection, a pseudoaneurysm was found in the parietal division of the left STA. The pseudoaneurysm was resected with ligation of the proximal and distal ends of the STA. The post-operative evolution was favorable (Figure 4 and 5).

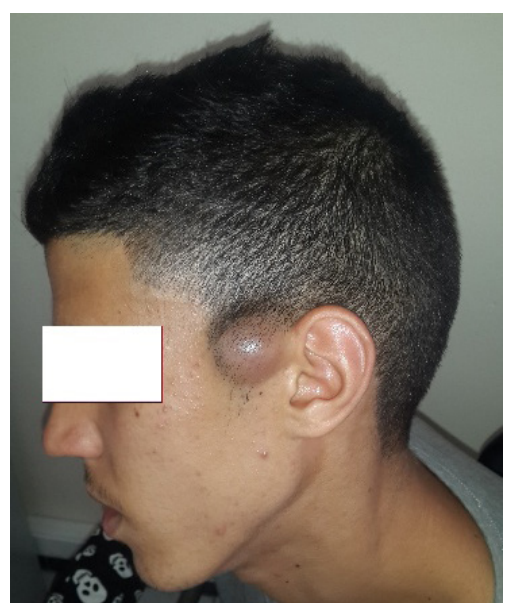

Figure 1: Photograph shows a round mass (arrows) in the left temporal region 


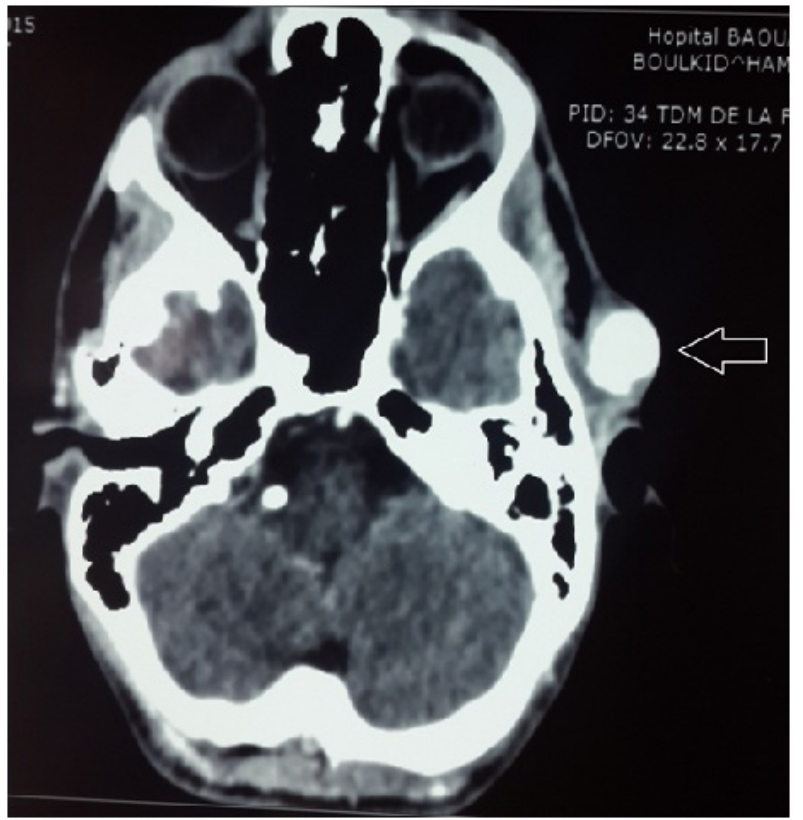

Figure 2: Contrast-enhanced computed tomography scan shows a wellenhancinground mass (arrows) in the left temporal region

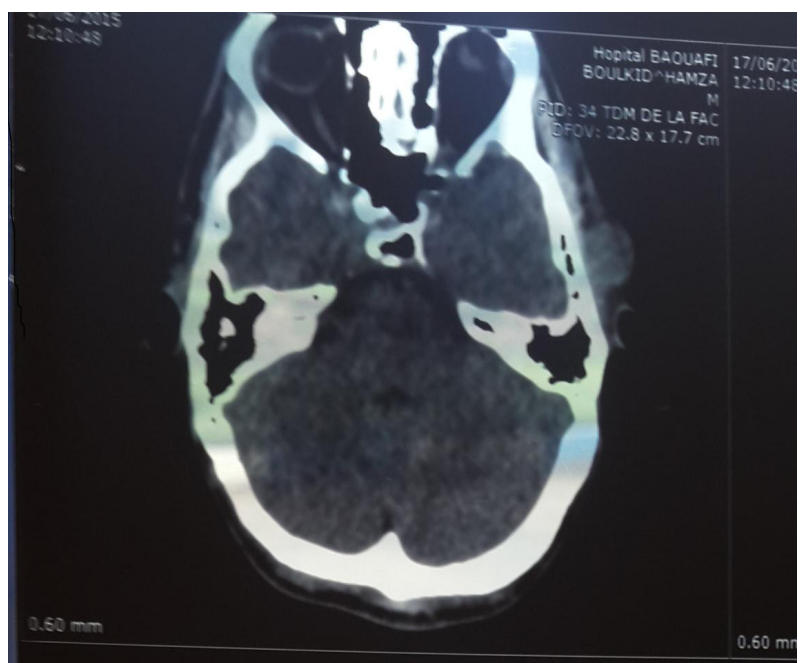

Figure 3: Computed tomography scan shows a round mass in the left temporal region

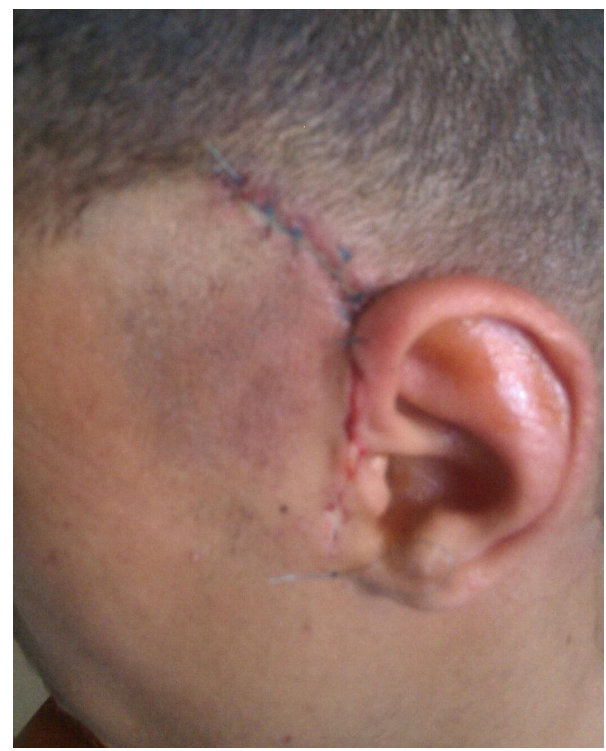

Figure 4: Post operative photograph ( $7^{\text {th }}$ day) 


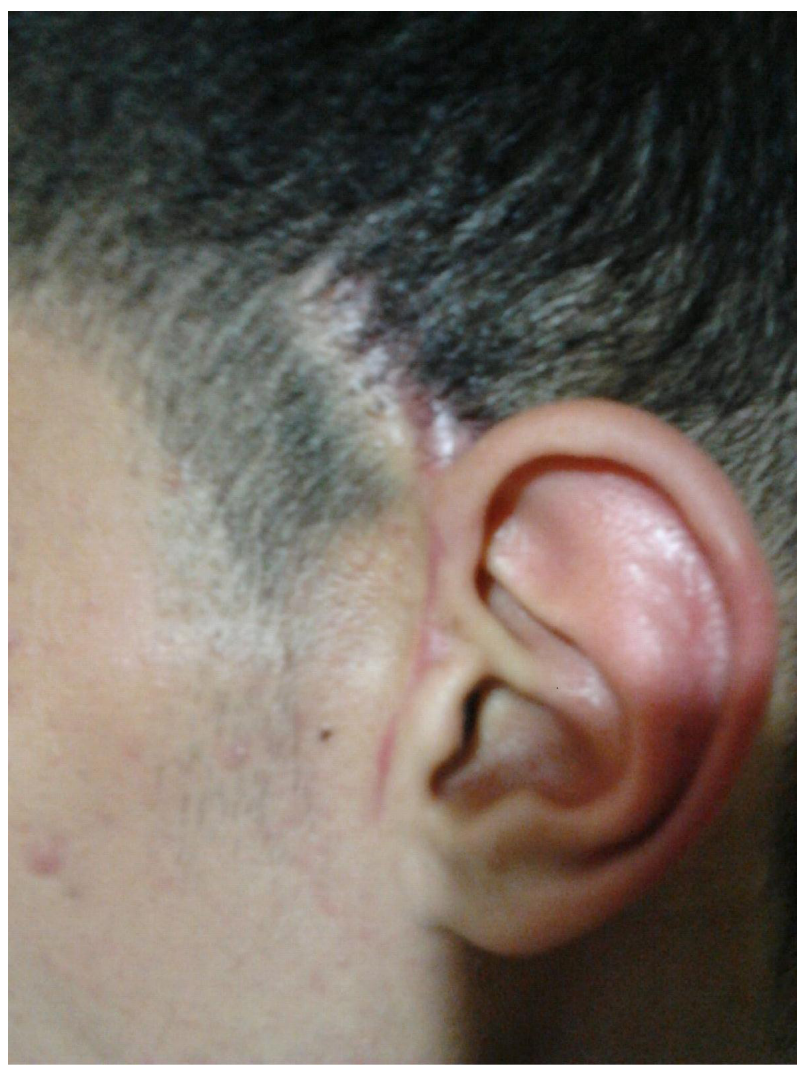

Figure 5: Post operative photograph (30 th day)

\section{Discussion}

Unlike "true aneurysms" which are dilatation of the intact arterial wall, pseudoaneurysms result from total or partial rupture of the arterial wall generally secondary to trauma, with subsequent hematoma formation and organization. This leads to development of a sac encapsulated only by arterial adventitia or perivascular tissue $[5,6]$.

The most common cause of pseudoaneurysms is blunt trauma from sports-related injuries, missile injuries, and motor vehicle accidents. Penetrating injuries from lacerations, gunshot or stab wounds, and surgery can also cause pseudoaneurysms [4,7]. In addition, iatrogenic causes such as neurosurgical procedures of skull fixation or hair transplantation have been reported [2,4]. Pseudoaneurysm of the STA most commonly affects men [6]. Some pediatric cases have been reported [2,5,8]. Histological examination of the pseudoaneurysms will demonstrate the lack of involvement of all three layers of the arterial wall, in contrast to true aneurysms [9]. The diagnosis of a STA pseudoaneurysm is based primarily on history and physical examination. Patients usually have a history of a traumatic event several weeks or months before the development of the mass. On examination, the mass is pulsatile in synchronony with the heartbeat, and a bruit can be auscultated over the mass. With proximal compression of the STA, the pulsations can diminish or the mass can disappear. Differential diagnosis should include epidermal inclusion cyst, lipoma, simple hematoma, abscess, enlarged lymph node, and neuroma of the supraorbital nerve [1,10]. Imaging methods such as Doppler ultrasonography or CTA can be used to confirm the diagnosis and exclude other conditions. In most cases, Doppler ultrasonography is the preferred initial imaging modality over CTA, so the use of contrast agent can be avoided. STA pseudoaneurysms require treatment to reduce the risk of hemorrhage from trauma to relieve pain and to resolve the cosmetic defect $[11,12]$. Excision and ligation of the proximal and distal ends of the STA has been the standard treatment. In addition, embolization has become a widely used modality in the treatment of vascular abnormalities, with successful occlusion of the STA pseudoaneurysm was reported in the literature. However, possible complications such as occlusion of the underlying artery, ischemic stroke following non-target embolization and autolysis of the embolization material over time should be considered [13-15].

\section{Conclusion}

A thorough history and physical examination are mandatory to make the diagnosis of STA pseudoaneurysms in patients with pulsatile lesions in forehead or scalp. Imaging modalities such as Doppler ultrasonography and CTA are helpful in confirming diagnosis and excluding other conditions. Surgical resection of the pseudoaneurysm and ligation of the proximal and distal ends of the STA is the preferred treatment option. 


\section{References}

1. Levisianos I, Sood V (2008) Traumatic aneurysm (pseudoaneurysm) of the superficial temporal artery. Emerg Med J 25: 239-40.

2. Quereshy FA, Choi S, Buma B (2008) Traumatic pseudoaneurysm of the superficial temporal artery in a pediatric patient: a case report. J Oral Maxillofac Surg 66: $133-5$.

3. Han K, Borah GL (1996) Pseudoaneurysm of the anterior superficial temporal artery. Ann Plast Surg 37: 650-3.

4. Conner WC, Rohrich RJ, Pollock RA (1998) Traumatic aneurysms of the face and temple: a patient report and literature review, 1644 to 1998 . Ann Plast Surg 41: 321-6.

5. Stewart CL, Cohen-Kerem R, Ngan BY, Forte V (2004) Post-traumatic facial artery aneurysm in a child. Int J Pediatr Otorhinolaryngol 68: 1539-43.

6. Chatelain B, Meyer C, Vitte F, Ricbourg B (2009) False aneurysm of the superficial temporal artery: report of two cases. Rev Stomatol Chir Maxillofac 110: 299302.

7. Walker MT, Liu BP, Salehi SA, Badve S, Batjer HH (2003) Superficial temporal artery pseudoaneurysm: diagnosis and preoperative planning with CT angiography. AJNR Am J Neuroradiol 24: 147-50.

8. Ahn HS, Cho BM, Oh SM, Park SH (2010) Traumatic pseudoaneurysm of the superficial temporal artery in a child: a case report. Childs Nerv Syst 26: 117-20.

9. Johnston KW, Rutherford RB, Tilson MD, Shah DM, Hollier L, et al. (1991) Suggested standards for reporting on arterial aneurysms. Subcommittee on reporting standards for arterial aneurysms, ad hoc committee on reporting standards, society for vascular surgery and north american chapter, international society for cardiovascular surgery. J Vasc Surg 13: 452-8.

10.Evans CC, Larson MJ, Eichhorn PJ, Taylor RS (2003) Traumatic pseudoaneurysm of the superficial temporal artery: two cases and review of the literature. J Am Acad Dermatol 49: S286-8.

11. Fox JT, Cordts PR, Gwinn BC (1994) Traumatic aneurysm of the superficial temporal artery: case report. J Trauma 36: 562-4.

12. Cremone JC, Grosh JD (1980) Traumatic aneurysms of the superficial temporal artery. J Trauma 20: 986-8.

13. Mann GS, Heran MK (2007) Percutaneous thrombin embolization of a post-traumatic superficial temporal artery pseudoaneurysm. Pediatr Radiol 37: 578-80.

14. Bobinski L, Bostrom S, Hillman J, Theodorsson A (2004) Postoperative pseudoaneurysm of the superficial temporal artery (S.T.A.) treated with thrombostat (thrombin glue) injection. Acta Neurochir (Wien) 146: 1039-41.

15. Sanchez F, Delgado F, Ramos M (2000) Pseudoaneurysm of the superficial temporal artery treated by embolization: report of a case. J Oral Maxillofac Surg 58: 819-21. 